\title{
Erratum to: Picosecond pulsed infrared laser tuned to amide I band dissociates polyglutamine fibrils in cells
}

\author{
Takayasu Kawasaki ${ }^{1} \cdot$ Gaku Ohori $^{1}$ - Tomoyuki Chiba ${ }^{1}$ Koichi Tsukiyama ${ }^{1}$. \\ Kazuhiro Nakamura ${ }^{2}$
}

Published online: 10 August 2016

(C) Springer-Verlag London 2016

Erratum to: Lasers Med Sci

DOI:10.1007/s10103-016-2004-x

The original version of this article, unfortunately, contained an error in Figure 2.
Figure $2 \mathrm{~d}$ was repeated and Figure $2 \mathrm{e}$ was missing in the original version.

Shown on this article is the correct Figure 2.

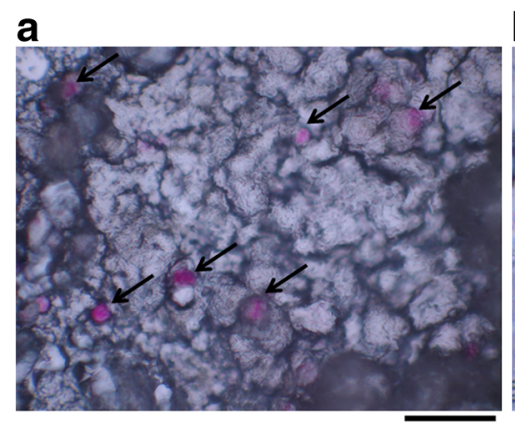

b

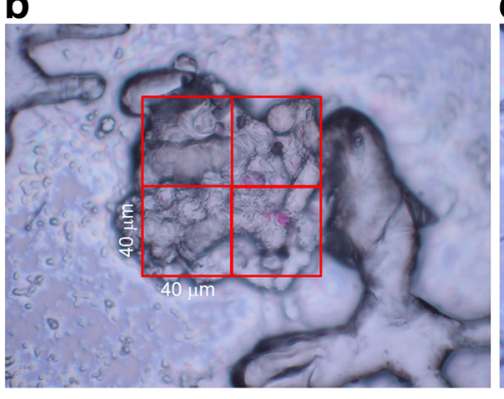

C

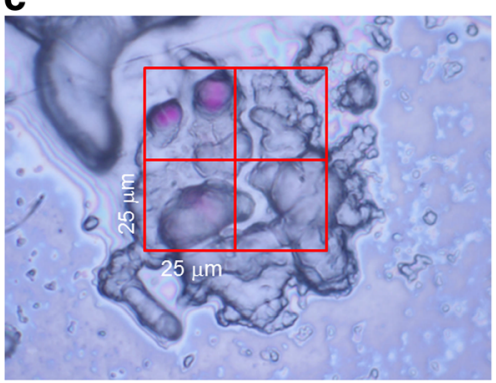

The online version of the original article can be found at http://dx.doi.org/ 10.1007/s10103-016-2004-x.

Kazuhiro Nakamura

knakamur@gunma-u.ac.jp

1 IR Free Electron Laser Research Center, Research Institute for Science and Technology, Organization for Research Advancement, Tokyo University of Science, 2641, Yamazaki, Noda, Chiba 278-8510, Japan

2 Department of Laboratory Sciences, Gunma University Graduate School of Health Sciences, 3-39-22, showa-machi, Maebashi, Gunma 371-8511, Japan 

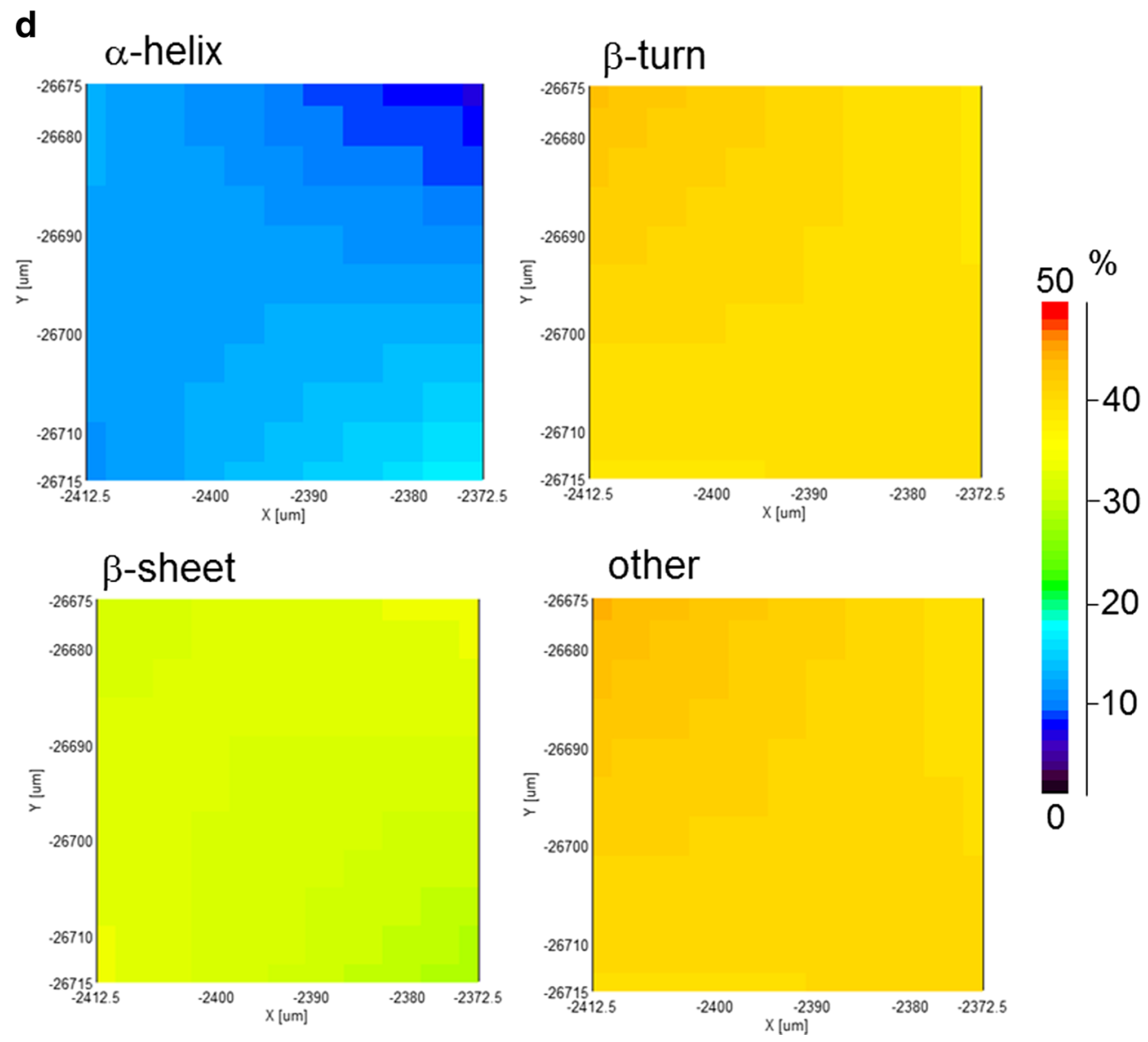


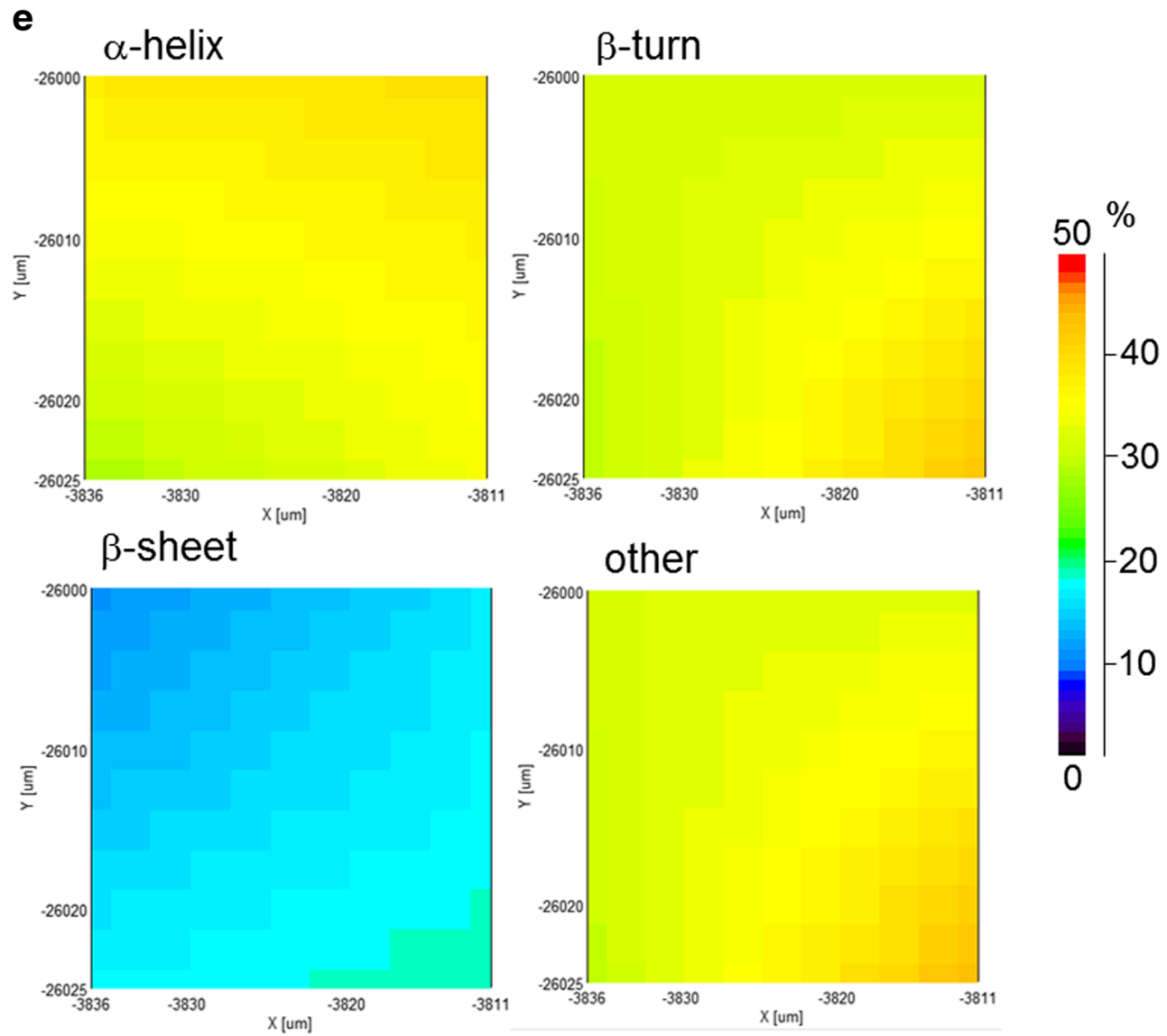

